\title{
Short Communication Body size and thyroid cancer in two million Norwegian men and
} women

\author{
A Engeland ${ }^{*, 1,2}$, S Tretli $^{3}$, LA Akslen $^{4}$ and T Bjørge ${ }^{2,5}$ \\ 'Division of Epidemiology, Nonwegian Institute of Public Health, PO Box 4404, N-0403 Oslo, Nonway; ${ }^{2}$ Department of Public Health and Primary Health \\ Care, Section for Epidemiology and Medical Statistics, University of Bergen, N-50 I 8 Bergen, Norway; ${ }^{3}$ The Cancer Registry of Norway, Institute of \\ Population-Based Cancer Research, Montebello, N-03 10 Oslo, Nonway; ${ }^{4}$ The Gade Institute, Section for Pathology, University of Bergen, N-5020 Bergen, \\ Norway; ${ }^{5}$ Division of Epidemiology, Norwegian Institute of Public Health, N-50 8 Bergen, Norway
}

We investigated relations between measured body mass index (BMI) and stature and thyroid cancer (3046 cases) in a large Norwegian cohort of more than two million individuals. The risk of thyroid cancer, especially of the papillary and follicular types, increased moderately with increasing $\mathrm{BMI}$ and height in both sexes.

British Journal of Cancer (2006) 95, 366-370. doi: I 0.1038/sj.bjc.6603249 www.bjcancer.com

Published online II July 2006

(c) 2006 Cancer Research UK

Keywords: thyroid cancer; body mass index; height; cohort study; Norway

Several types of malignancies have been associated with increased weight, as summarised recently (IARC Working Group on the Evaluation of Cancer-Preventive Strategies, 2002). As thyroid cancer is relatively rare, with only a few studies of its association with obesity, the working group did not include it in its review.

In 1993-1997, thyroid cancer comprised 0.5 and $1.4 \%$ of all male and female cancer cases, respectively, in the Nordic countries (Møller et al, 2002). In Norway, the (world) age-adjusted incidence rates in 2004 were 1.5 and 5.1 per 100000 persons per year in men and women, respectively (The Cancer Registry of Norway, 2006), the higher rates among women being typical (Parkin et al, 2005). In the US, the rates of thyroid cancer are significantly higher and increasing. In 2001, the age-adjusted incidence rates were 4.2 and 12 per 100000 persons per year in males and females (National Cancer Institute, 2005).

In the present study, we used measurements from Norwegian health surveys to examine the relations between body mass index (BMI) and stature and the risk of thyroid cancer. We have recently published similar analyses for a range of cancers (Engeland et al, 2003a-c, 2004, 2005; Bjørge et al, 2004).

\section{MATERIALS AND METHODS}

The study population and the methods have been described elsewhere (Bjørge et al, 2004). In a number of Norwegian health surveys during 1963-2001, height and weight were measured in 2001727 persons (963 709 men and 1038018 women) aged 20-74 years in a standardised way by a trained staff. A major part of the health surveys in the period 1963-1975 was included in a nationwide tuberculosis screening programme (Waaler, 1984), which was compulsory for all Norwegians aged 15 years and above;

*Correspondence: Professor A Engeland;

E-mail: anders.engeland@isf.uib.no

Received 27 April 2006; revised 5 June 2006; accepted 9 June 2006; published online II July 2006 attendance was about 85\%. In 1963-1964 and in 1972-2001, height and weight were also measured in other health surveys connected with coronary heart disease in different parts of Norway (Bjartveit et al, 1979; Bjartveit, 1997). The attendance in these surveys in the mid-1970s was $85-90 \%$ and about $75 \%$ in the mid1990s (Bjartveit, 1997).

Deaths, emigrations and cases of thyroid cancer (International Classification of Diseases, seventh revision (ICD-7): 194) in this cohort were identified by linkage to the Death Registry at Statistics Norway (Statistics Norway, 2006) and to the Cancer Registry of Norway (The Cancer Registry of Norway, 2006). Both these registries are population based and cover the entire Norwegian population. A unique 11-digit identification number assigned to all individuals living in Norway after 1960 facilitated the linkages.

The present study included only histologically verified thyroid cancers. Persons with a diagnosis of thyroid cancer before the height and weight measurements were excluded $(n=709)$. In the analyses, the persons in the cohort were followed from the date of measurement until the date of cancer diagnosis, emigration, age 100 years, death or until 31 December 2003. Altogether, 2001018 persons were eligible for the study. A small number of these (39 men and 32 women) were lost to follow-up.

\section{Statistical methods}

Cox's proportional hazards regression models (Cox and Oakes, 1984), with time since measurement as the time variable, were fitted to obtain relative risk estimates of cancer. In the analyses, categorised variables for age at measurement, year of birth, BMI ((weight in kilograms)/(height in metres) ${ }^{2}$ ) and height were included. Body mass index was categorised using the WHO categorisation (World Health Organization Consultation on Obesity, 1998): BMI <18.5 (underweight), 18.5-24.9 (normal), $25.0-29.9$ (preobese/overweight) and $\geqslant 30.0 \mathrm{~kg} / \mathrm{m}^{2}$ (obese).

Analyses were also performed treating BMI and height, respectively, as continuous variables to test for trend in thyroid 
cancer risk. Separate analyses were performed for papillary, follicular, medullary, anaplastic, other carcinomas and other malignant tumours. All these analyses were performed with the statistical program package SPSS (SPSS Inc., SPSS for Windows, Release 12.0.2.2004). The results were presented as relative risks (RR) of cancer with $95 \%$ confidence intervals (CI). The hazard functions of thyroid cancer by BMI and height in the Cox model were estimated using spline functions in S-plus (Insightful Corporation, 2002), with 4 d.f.

\section{RESULTS}

The 2000947 persons (963523 men and 1037424 women) included in this study were followed for on average 23 years (maximum 41 years), constituting 47 million person-years (Table 1). The mean age at measurement was 44 years, and the proportions of obesity were 6 and $13 \%$ in men and women, respectively. During follow-up, 3046 thyroid cancer cases were diagnosed among the study subjects on average 15 years after the measurements. The mean age at diagnosis was 62.2 and 57.7 years in men and women, respectively.

The risk of thyroid cancer increased moderately by increasing BMI in both sexes (Table 2). The RR of thyroid cancer per unit increase in BMI was 1.03 (95\% CI: $1.00-1.05$ ) in men and 1.02 (95\% CI: 1.01-1.03) in women. Excluding the first 5 years of follow-up did not change these results. Splitting the upper BMI category in women gave RRs of 1.27 (95\% CI: $1.11-1.47), 1.33$ (95\% CI: $1.03-1.73)$ and 1.38 (95\% CI: $0.83-2.30)$ with BMI of $30.0-34.9,35.0-39.9$ and 40 or above, respectively, compared with normal-weighted women.

Histology-specific analyses revealed that the relative risk of follicular carcinoma increased more than the risk of papillary carcinoma with increasing BMI. Further, the risk of medullary carcinoma tended to decrease with increasing BMI in both sexes, being significant among females only. The RR of medullary carcinoma per unit increase in BMI was 0.94 (95\% CI: 0.85-1.04) in men and 0.91 (95\% CI: $0.86-0.97)$ in women. The number of cases was low (52 and 107 medullary carcinomas in men and women, respectively). The anaplastic carcinomas showed a strong positive association with BMI in men.

The risk of thyroid cancer increased with increasing height in both sexes (Table 2). The RR of thyroid cancer associated with $10 \mathrm{~cm}$ increase in height was 1.18 (95\% CI: 1.05-1.32) in men and 1.22 (95\% CI: $1.13-1.31)$ in women.

Among males, the elevated risk associated with increased BMI was confined to those measured at the age of 50-74 years (Table 3).

Table I Number of observed cases of thyroid cancer, person-years and overall incidence rates

\begin{tabular}{|c|c|c|c|c|c|c|}
\hline \multirow[b]{2}{*}{ Variable } & \multicolumn{3}{|c|}{ Men } & \multicolumn{3}{|c|}{ Women } \\
\hline & No. of cases & Person-years & Incidence rate ${ }^{a}$ & No. of cases & Person-years & Incidence rate ${ }^{a}$ \\
\hline \multicolumn{7}{|c|}{ Time since measurement } \\
\hline $0-4$ & || $\mid$ & 4703991 & 2 & 373 & $510 \mid 421$ & 7 \\
\hline $5-9$ & 129 & 4185673 & 3 & 408 & 4626652 & 9 \\
\hline $10-14$ & 138 & 3538321 & 4 & 388 & 4037840 & 10 \\
\hline $15-19$ & 117 & 2973578 & 4 & 380 & 3549515 & || \\
\hline $20-24$ & 115 & 2513972 & 5 & 302 & 3129190 & 10 \\
\hline $25-29$ & 110 & 2099195 & 5 & 254 & 2710836 & 9 \\
\hline$\geqslant 30$ & 58 & 537708 & 4 & 163 & 2154886 & 8 \\
\hline \multicolumn{7}{|l|}{ Age at measurement } \\
\hline $20-29$ & 102 & 4857330 & 2 & 424 & 5592525 & 8 \\
\hline $30-39$ & 125 & 4646552 & 3 & 445 & $527459 \mid$ & 8 \\
\hline $40-49$ & 249 & 6527602 & 4 & 585 & 7032741 & 8 \\
\hline $50-59$ & 181 & $3457 \mid 35$ & 5 & 471 & 4461529 & | | \\
\hline $60-69$ & 103 & | 702823 & 6 & 279 & 2421213 & 12 \\
\hline $70-74$ & 18 & 360996 & 5 & 64 & 527742 & 12 \\
\hline \multicolumn{7}{|l|}{ Year of birth } \\
\hline$<1900$ & 23 & 468282 & 5 & 71 & 685680 & 10 \\
\hline $1900-1909$ & 103 & | 775347 & 6 & 290 & 2553276 & | | \\
\hline $1910-1919$ & 191 & 3513545 & 5 & 478 & 4548443 & || \\
\hline $1920-1929$ & 200 & 4993652 & 4 & 491 & 5567701 & 9 \\
\hline $1930-1939$ & 119 & 4316383 & 3 & 379 & 4830007 & 8 \\
\hline $1940-1949$ & 108 & 4645330 & 2 & 411 & 5106836 & 8 \\
\hline$\geqslant 1950$ & 34 & | 839899 & 2 & 148 & 2018398 & 7 \\
\hline \multicolumn{7}{|l|}{$\mathrm{BMI}\left(\mathrm{kg} / \mathrm{m}^{2}\right)$} \\
\hline$<18.5$ & 2 & 138637 & 1 & 30 & 549113 & 5 \\
\hline $18.5-24.9$ & 412 & 12572703 & 3 & 1187 & 14418940 & 8 \\
\hline $25.0-29.9$ & 322 & 7837913 & 4 & 710 & 7426823 & 10 \\
\hline$\geqslant 30.0$ & 42 & | 003 | 85 & 4 & 341 & 2915463 & 12 \\
\hline \multicolumn{7}{|l|}{ Height $(\mathrm{cm})^{\mathrm{b}}$} \\
\hline$<150$ & & & & 28 & 366766 & 8 \\
\hline$<160 / 150-159$ & 8 & 143556 & 6 & 628 & 7042763 & 9 \\
\hline $160-169$ & 116 & 3323324 & 3 & 1,247 & |459| 487 & 9 \\
\hline$|70-| 79 \mid \geqslant 170$ & 429 & II 760603 & 4 & 365 & 3309325 & || \\
\hline$\geqslant 180$ & 225 & 6324955 & 4 & & & \\
\hline Total & 778 & 21552438 & 4 & 2268 & 25310340 & 9 \\
\hline
\end{tabular}

Abbreviations: BMI = body mass index. ${ }^{a}$ Number of thyroid cancer cases per 100000 person-years. ${ }^{b}$ Split categories pertain to men and women, respectively. 
Table 2 RR of thyroid cancer with 95\% Cl obtained in Cox's regression analyses; age at measurements and birth cohort were included in the model in addition to either $\mathrm{BMI}$ or height ${ }^{\mathrm{a}}$

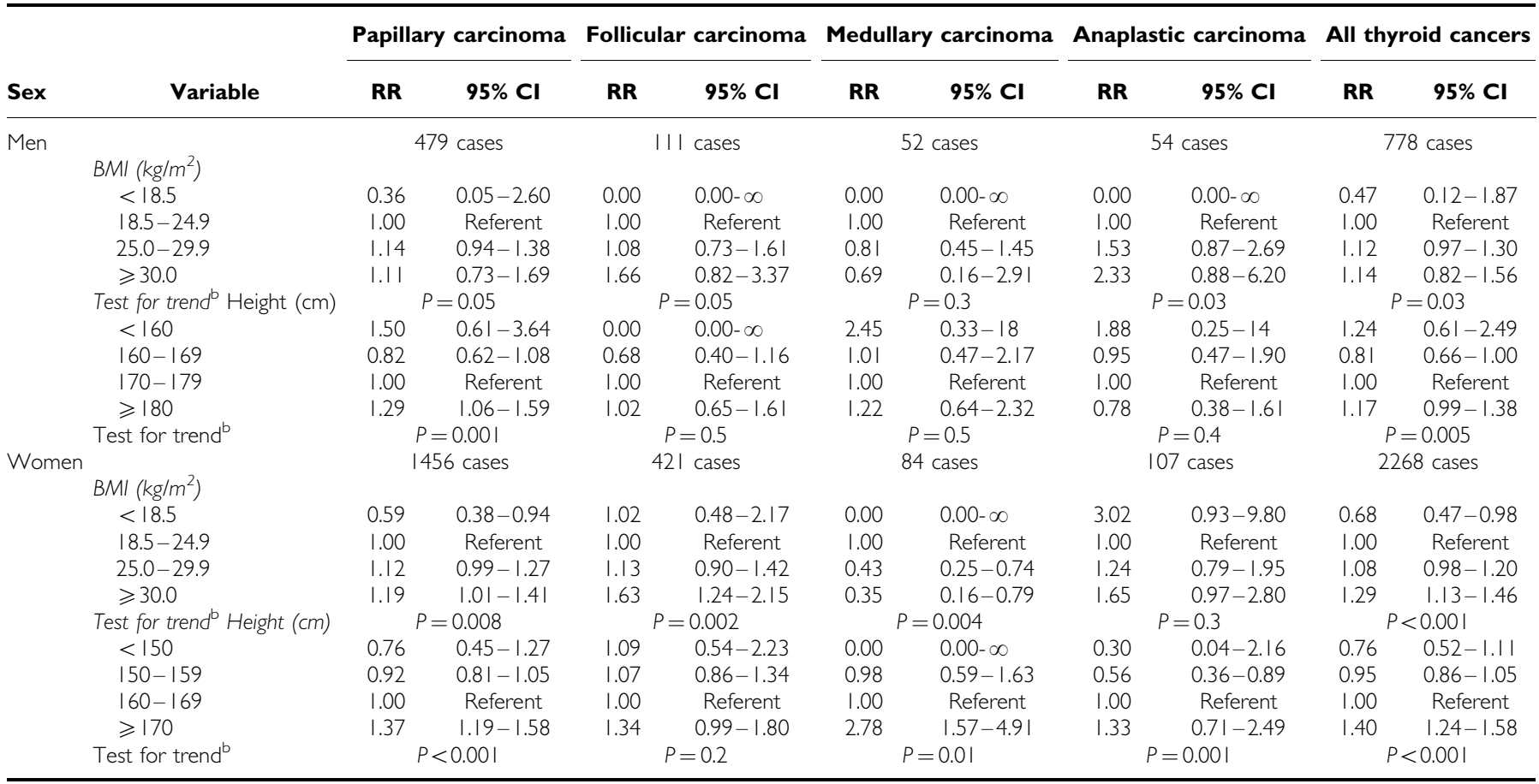

Abbreviations:BMI = body mass index, $\mathrm{Cl}=$ confidence interval, $\mathrm{RR}=$ relative risk. ${ }^{\mathrm{a}}$ Year of birth and age at measurement were included as continuous variables when number of cases was less than 150. ${ }^{\mathrm{b}} \mathrm{BMI}$ and height, respectively, were included as continuous variables.

Table 3 RR of thyroid cancer with 95\% Cl obtained in Cox's regression analyses; age at measurements and birth cohort were included in the model in addition to either body mass index or height. Analysis stratified on age at measurement

Thyroid cancer

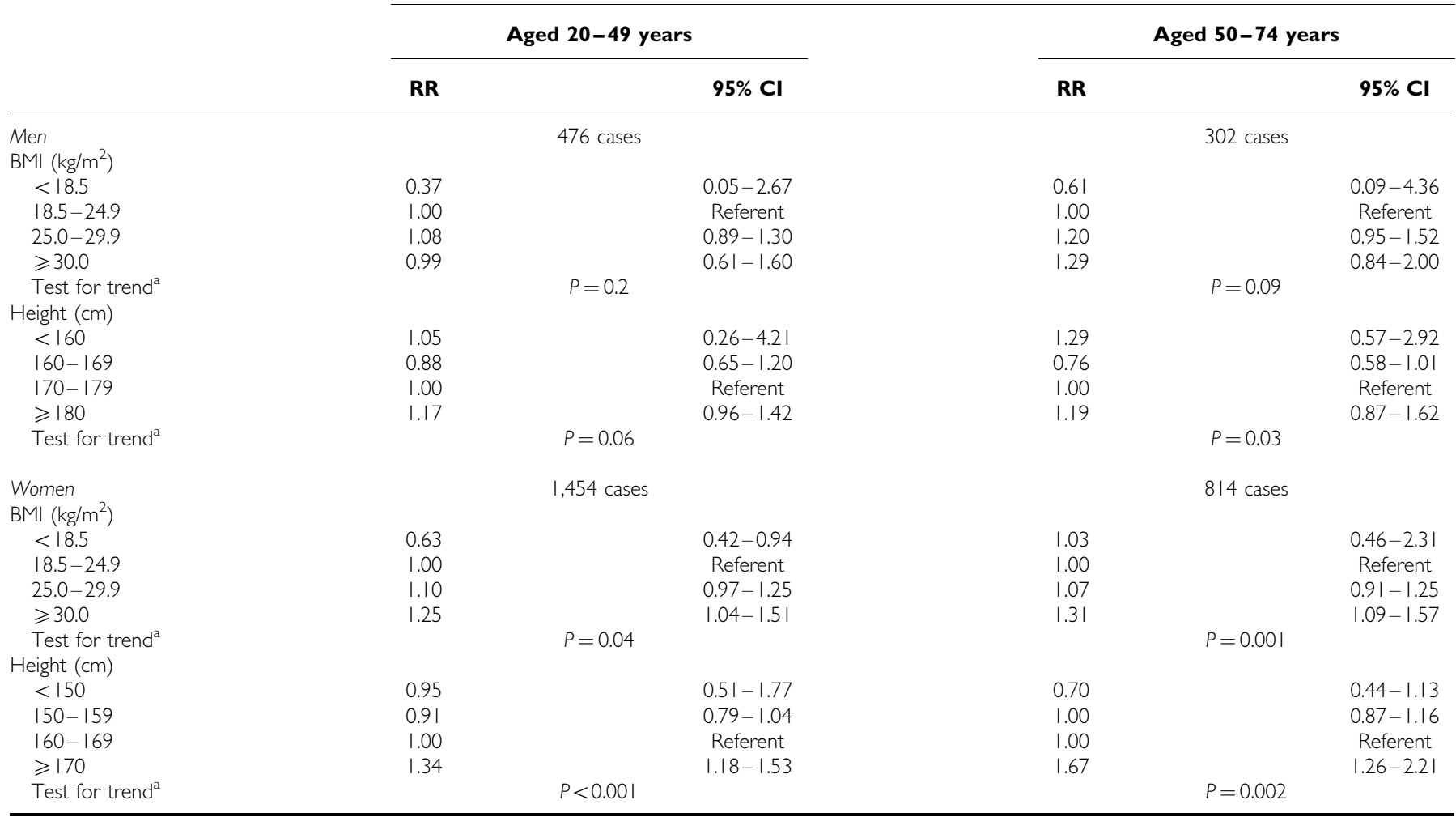

Abbreviations: $\mathrm{BMI}=$ body mass index, $\mathrm{Cl}=$ confidence interval, $\mathrm{RR}=$ relative risk. ${ }^{\mathrm{a}} \mathrm{BMI}$ and height, respectively, were included as continuous variables. 

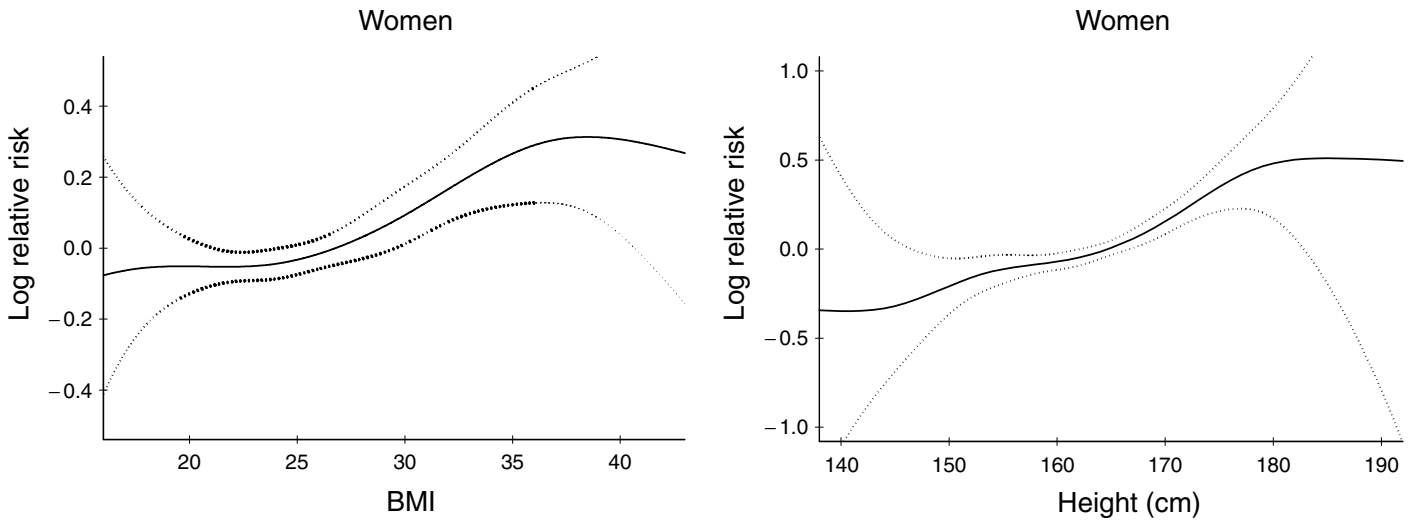

Figure I Logarithm of the relative risk of thyroid cancer, with $95 \% \mathrm{Cls}$, from penalised spline functions with 4 d.f. Adjusted for birth cohort and age at measurements.

The associations between BMI and stature and the risk of thyroid cancer in women are illustrated in Figure 1. The risk of thyroid cancer increased with increasing height and BMI above $25 \mathrm{~kg} / \mathrm{m}^{2}$.

\section{DISCUSSION}

In this large cohort, including more than two million individuals, we explored the associations between BMI and height and the occurrence of thyroid cancer. The risk was found to be moderately elevated with increasing BMI and height in both sexes among the follicle-cell derived (papillary and follicular) carcinomas. In medullary carcinomas, an opposite trend was present for BMI, pointing to a different pathogenetic influence.

The associations between BMI and height with thyroid cancer have been difficult to explore in previous small studies owing to the low incidence of this disease. In addition to the large size of the present cohort, we also had an almost complete follow-up with regard to thyroid cancer incidence and deaths. This was made possible by linkages to population-based registries of high quality. Only $0.04 \%$ of the study cohort (71 persons) was lost to follow-up, and $0.6 \%$ was censored by emigration from Norway.

After a pooled analysis of 12 case-control studies, including 2473 cases, Dal Maso et al (2000) previously found a moderately increased risk of thyroid cancer related to height and weight at diagnosis. Dal Maso et al (2000) used self-reported values for height and weight during the late teens and at diagnosis. In the present study, we relied on height and weight measurements performed on average 15 years before the diagnosis of thyroid cancer. Hence, our estimates were not diluted by a possible influence of individuals weight on the disease.

\section{REFERENCES}

Bjartveit K (1997) [The National Health Screening Service: from fight against tuberculosis to many-sided epidemiological activities] Fra tuberkulosekamp til mangesidig epidemiologisk virksomhet. Nor Epidemiol 7: $157-174$

Bjartveit K, Foss OP, Gjervig T, Lund-Larsen PG (1979) The cardiovascular disease study in Norwegian counties. Background and organization. Acta Med Scand Suppl 634: 1-70

Bjørge T, Tretli S, Engeland A (2004) Relation of height and body mass to renal cell carcinoma in two million Norwegian men and women. Am J Epidemiol 160: $1168-1176$

Cox DR, Oakes D (1984) Analysis of Survival Data. London: Chapman \& Hall Ltd

Dal Maso L, La Vecchia C, Franceschi S, Preston-Martin S, Ron E, Levi F, Mack W, Mark SD, McTiernan A, Kolonel L, Mabuchi K, Jin F, Wingren
Iribarren et al (2001) evaluated several potential predictors of thyroid cancer in a large American cohort with long follow-up, including more than 200000 persons. Despite the large size of the cohort and the long follow-up, only 196 thyroid cancers were observed. In this study, no association between BMI, height or weight gain and thyroid cancer was observed.

Dal Maso et al (2000) hypothesised that an association between BMI and thyroid cancer could be owing to a relationship with steroid hormones or other endocrine factors. However, they observed an association between BMI and thyroid cancer of similar magnitude in older and younger women. Also in the present study, there was no difference in the association between BMI and thyroid cancer in older and younger women.

Like Dal Maso et al (2000), we observed a moderately increasing risk of thyroid cancer with increasing height. This association may be owing to dietary influence during childhood or adolescence and possible interactions with growth factors.

In conclusion, the present study showed that the risk of thyroid cancer increased moderately with increasing BMI and height in both males and females.

\section{ACKNOWLEDGEMENTS}

We are grateful to those who for almost 40 years collected the data used in the present study. These people were connected to the former National Health Screening Service, The Nord-Trøndelag Health Survey (HUNT), The Hordaland Health Survey (HUSK) and The Tromsø Study.
G, Galanti MR, Hallquist A, Glattre E, Lund E, Linos D, Negri E (2000) A pooled analysis of thyroid cancer studies. V. Anthropometric factors. Cancer Causes Control 11: 137-144

Engeland A, Bjørge T, Selmer RM, Tverdal A (2003a) Height and body mass index in relation to total mortality. Epidemiology 14: 293-299

Engeland A, Tretli S, Austad G, Bjørge T (2005) Height and body mass index in relation to colorectal and gallbladder cancer in two million Norwegian men and women. Cancer Causes Control 16: 987 - 996

Engeland A, Tretli S, Bjørge T (2003b) Height, body mass index, and ovarian cancer: a follow-up of 1.1 million Norwegian women. J Natl Cancer Inst 95: 1244-1248

Engeland A, Tretli S, Bjørge T (2003c) Height, body mass index, and prostate cancer: a follow-up of 950000 Norwegian men. Br J Cancer 89: $1237-1242$ 
Engeland A, Tretli S, Bjørge T (2004) Height and body mass index in relation to esophageal cancer; 23-year follow-up of two million Norwegian men and women. Cancer Causes Control 15: $837-843$

IARC Working Group on the Evaluation of Cancer-Preventive Strategies (2002) Weight Control and Physical Activity. Lyon: IARC Press International Agency for Research on Cancer

Insightful Corporation (2002) S-plus 6.1 for windows. Insightful Corporation

Iribarren C, Haselkorn T, Tekawa IS, Friedman GD (2001) Cohort study of thyroid cancer in a San Francisco Bay area population. Int J Cancer 93: $745-750$

Møller B, Fekjær H, Hakulinen T, Tryggvadóttir L, Storm HH, Tallbäck M, Haldorsen T (2002) Prediction of cancer incidence in the Nordic countries up to the year 2020. Eur J Cancer Prev 11(Suppl 1): S1-S96
National Cancer Institute (2005) SEER Cancer Statistics Review, 1975 - 2001, http://seer.cancer.gov/csr/1975_2001/ Ries LAG, Eisner MP, Kosary CL, Hankey BF, Miller AB, Clegg L, Mariotto A, Feuer EJ, and Edwards BK (ed) March 2005, National Cancer Institute

Parkin DM, Bray F, Ferlay J, Pisani P (2005) Global cancer statistics, 2002. CA Cancer J Clin 55: 74-108

Statistics Norway (2006) Statistics Norway. http://www.ssb.no/english/ April 2006

The Cancer Registry of Norway (2006) The Cancer Registry of Norway. http://www.kreftregisteret.no/ April 2006

Waaler HT (1984) Height, weight and mortality. The Norwegian experiment. Acta Med Scand 679 (Suppl): 1-56

World Health Organization Consultation on Obesity (1998) Preventing and managing the global epidemic: Report of a WHO Consultation on Obesity, Geneva, 3-5 June 1997, pp 1-276. 1998. Geneva, Switzerland: World Health Organization 